Canadian

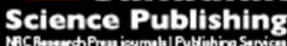

Applied Physiology, Nutrition, and Metabolism Physiologie appliquée, nutrition et métabolisme

\title{
Estimating peak oxygen uptake based on postexercise measurements in swimming
}

\begin{tabular}{|c|c|}
\hline Journal: & Applied Physiology, Nutrition, and Metabolism \\
\hline Manuscript ID & apnm-2015-0524.R1 \\
\hline Manuscript Type: & Article \\
\hline Date Submitted by the Author: & 10-Dec-2015 \\
\hline Complete List of Authors: & $\begin{array}{l}\text { Chaverri, Diego; Institut Nacional d'Educació Física de Catalunya, } \\
\text { Universitat de Barcelona, INEFC-Barcelona Sport Sciences Research Group } \\
\text { Iglesias, Xavier; Institut Nacional d'Educació Física de Catalunya, } \\
\text { Universitat de Barcelona, INEFC-Barcelona Sport Sciences Research Group } \\
\text { Schuller, Thorsten; Deutsche Sporthochschule Köln, Institut für Physiologie } \\
\text { und Anatomie } \\
\text { Hoffmann, Uwe; Deutsche Sporthochschule Köln, Institut für Physiologie } \\
\text { und Anatomie } \\
\text { Rodríguez, Ferran; Institut Nacional d'Educació Física de Catalunya, } \\
\text { University of Barcelona, INEFC-Barcelona Sport Sciences Research Group }\end{array}$ \\
\hline Keyword: & VO2max, oxygen kinetics, heart rate, backward extrapolation, modelling \\
\hline
\end{tabular}




\section{Estimating peak oxygen uptake based on postexercise measurements in swimming}

Diego Chaverri. INEFC-Barcelona Sport Sciences Research Group, Institut Nacional d’Educació Física de Catalunya, Universitat de Barcelona. Av. de l'Estadi, 12-22, 08038 Barcelona (Spain). Tel.: +34 934255445. E-mail: chaverri.diego@gmail.com

Xavier Iglesias. INEFC-Barcelona Sport Sciences Research Group, Institut Nacional d'Educació Física de Catalunya, Universitat de Barcelona. Av. de l'Estadi, 12-22, 08038 Barcelona (Spain). Tel.: +34 934255445. E-mail: xiglesias@gencat.cat

Thorsten Schuller. Institut für Physiologie und Anatomie, Deutsche Sporthochschule Köln, Am Sportpark Müngersdorf 6, 50933 Köln (Germany).Tel.: +49 17682135050. Email: thorsten.schuller@web.de

Uwe Hoffmann. Institut für Physiologie und Anatomie, Deutsche Sporthochschule Köln, Am Sportpark Müngersdorf 6, 50933 Köln (Germany).Tel.: +49 17682135050. Email: u.hoffmann@,dshs-koeln.de

Ferran A. Rodríguez. INEFC-Barcelona Sport Sciences Research Group, Institut Nacional d'Educació Física de Catalunya, Universitat de Barcelona. Av. de 1'Estadi, 1222, 08038 Barcelona (Spain). Tel.: +34 934255445. E-mail: farodriguez@gencat.cat

Corresponding author: 
Prof. Ferran A. Rodríguez. INEFC-Barcelona Sport Sciences Research Group, Institut Nacional d'Educació Física de Catalunya, Universitat de Barcelona. Av. de l'Estadi, 1222, 08038 Barcelona (Spain). Tel.: +34 934255445. E-mail: farodriguez@gencat.cat 


\section{Abstract}

To assess the validity of postexercise measurements in estimating peak oxygen uptake $\left(\mathrm{V}^{\prime} \mathrm{O}_{2 \text { peak }}\right)$ in swimming, we compared $\mathrm{V}^{\prime} \mathrm{O}_{2}$ measurements during supramaximal exercise with various commonly adopted methods, including a recently developed heart rate- $\mathrm{V}^{\prime} \mathrm{O}_{2}$ modelling procedure. 31 elite swimmers performed a 200-m maximal swim where $\mathrm{V}^{\prime} \mathrm{O}_{2}$ was measured breath-by-breath using a portable gas analyser connected to a respiratory snorkel, $1 \mathrm{~min}$ before, during, and $3 \mathrm{~min}$ postexercise. $\mathrm{V}^{\prime} \mathrm{O}_{2 \text { peak }}(-20-0)$ was the average of the last $20 \mathrm{~s}$ of effort. The following postexercise measures were compared: 1) first 20-s average [ $\left.\mathrm{V}^{\prime} \mathrm{O}_{2 \text { peak }}(0-20)\right]$; 2) linear backward extrapolation (BE) of the first $20 \mathrm{~s}[\mathrm{BE}(20)], 30 \mathrm{~s}$, and $3 \times 20-, 4 \times 20$ - and $3-$ or $4 \times 20-\mathrm{s}$ averages; 3) semilogarithmic $\mathrm{BE}$ at $20 \mathrm{~s}[\mathrm{LOG}(20)]$ and at the other same time intervals as in linear $\mathrm{BE}$; and 4) predicted $\mathrm{V}^{\prime} \mathrm{O}_{2 \text { peak }}$ using mathematical modelling $\left[\mathrm{pV}^{\prime} \mathrm{O}_{2}(0-20)\right]$. ANOVA and post-hoc Bonferroni tests compared $\mathrm{V}^{\prime} \mathrm{O}_{2 \text { peak }}$ (criterion) and each estimated value. Pearson's coefficient of determination $\left(r^{2}\right)$ was used to assess correlation. Exercise $\mathrm{V}^{\prime} \mathrm{O}_{2 \text { peak }}(-20-0)\left(\right.$ mean $\left.\pm \mathrm{SD} 3531 \pm 738 \mathrm{ml} \cdot \mathrm{min}^{-1}\right)$ was not different $(p>0.30)$ from $\mathrm{pV}^{\prime} \mathrm{O}_{2}(0-20)\left(3571 \pm 735 \mathrm{ml} \cdot \mathrm{min}^{-1}\right), \mathrm{BE}(20)\left(3617 \pm 708 \mathrm{ml} \cdot \mathrm{min}^{-1}\right)$, or LOG(20) $\left(3627 \pm 746 \mathrm{ml} \cdot \mathrm{min}^{-1}\right) \cdot \mathrm{pV}^{\prime} \mathrm{O}_{2}(0-20)$ was very strongly correlated with exercise $\mathrm{V}^{\prime} \mathrm{O}_{2 \text { peak }}\left(r^{2}=0.962 ; p<0.001\right)$, and showed a low standard error of the estimate (146 $\left.\mathrm{ml} \cdot \mathrm{min}^{-1}, 4.1 \%\right)$ and the lowest mean difference $\left(40 \mathrm{ml} \cdot \mathrm{min}^{-1} ; 1.1 \%\right)$. We confirm that the new modelling procedure based on postexercise $\mathrm{V}^{\prime} \mathrm{O}_{2}$ and $\mathrm{HR}$ measurements is a valid and accurate procedure for estimating $\mathrm{V}^{\prime} \mathrm{O}_{2 \text { peak }}$ in swimmers and avoids the estimation bias produced by other methods.

Key words: $V^{\prime} \mathrm{O}_{2 \max }$; oxygen kinetics; heart rate; backward extrapolation; modelling 


\section{Résumé}

Pour élucider la validité des mesures post-exercice pour l'estimation de la consommation pic d'oxygène $\mathrm{V}^{\prime} \mathrm{O}_{\text {peak }}$ ) en natation, nous avons comparés diverses méthodes communément adoptées, y comprise une procédure de modélisation en base à la relation fréquence cardiaque- $\mathrm{V}^{\prime} \mathrm{O}_{2} .31$ nageurs d'élite ont nagé $200 \mathrm{~m}$ à intensité maximale. $\mathrm{V}^{\prime} \mathrm{O}_{2}$ a été mesurée en utilisant un analyseur de gaz portable connecté à un tuba respiratoire, 1 min avant, pendant et pendant 3 min après de l'effort. $\mathrm{V}^{\prime} \mathrm{O}_{2 \text { peak }}(-20-$ 0) été la moyenne des 20 dernières secondes de l'effort. Les suivantes mesures postexercice ont été comparées: 1) moyenne des premiers $\left.20-\mathrm{s}\left[\mathrm{V}^{\prime} \mathrm{O}_{2 \text { peak }}(0-20)\right] ; 2\right)$ rétroextrapolation linéaire des $20 \mathrm{~s}[\mathrm{BE}(20)]$ et des $30 \mathrm{~s}$ premières secondes, et moyennes des intervalles $2 \times 20 \mathrm{~s}, 3 \times 20 \mathrm{~s}$ et 3 ou $4 \times 20 \mathrm{~s} ; 3)$ rétroextrapolation semilogarithmique à $20 \mathrm{~s}$ [LOG(20)] et aux mêmes intervalles de temps que celle linéaire; et 4) modélisation mathématique sur $20 \mathrm{~s}\left[\mathrm{pV}^{\prime} \mathrm{O}_{2}(0-20)\right]$. Chaque valeur a été comparée avec $\mathrm{V}^{\prime} \mathrm{O}_{2 \text { peak }}$ (critère) utilisant l'analyse de la variance pour mesures répétées. Le coefficient de Pearson $\left(r^{2}\right)$ a été utilisé pour évaluer la corrélation. $\mathrm{V}^{\prime} \mathrm{O}_{2 \text { peak }}(-20-0)$ $\left(3531 \pm 738 \mathrm{ml} \cdot \mathrm{min}^{-1}\right)$ n'a pas été différente $(p>0.3)$ de $\mathrm{pV}^{\prime} \mathrm{O}_{2}(0-20)\left(3571 \pm 735 \mathrm{ml} \cdot \mathrm{min}^{-}\right.$

$\left.{ }^{1}\right), \mathrm{BE}(20)\left(3617 \pm 708 \mathrm{ml} \cdot \mathrm{min}^{-1}\right)$, ou $\operatorname{LOG}(20)\left(3627 \pm 746 \mathrm{ml} \cdot \mathrm{min}^{-1}\right) \cdot \mathrm{pV} \mathrm{O}^{\prime} 2(0-20)$ a été fortement corrélée avec $\mathrm{V}^{\prime} \mathrm{O}_{2 \text { peak }}(-20-0)\left(r^{2}=0,962 ; \mathrm{p}<0,001\right)$ et a montré une faible erreur type d'estimation $(4,1 \%)$ et la plus basse différence moyenne $(1,1 \%)$. On confirme que le nouveau modèle est une procédure valide et précise pour estimer la $\mathrm{V}^{\prime} \mathrm{O}_{2 \text { pic }}$ chez les nageurs, tout en évitant les biais d'estimation produits par d'autres méthodes.

Mots clés: $\mathrm{VO}_{2 \max }$; cinétique de l'oxygène; rythme cardiaque; cinétique de la fréquence cardiaque; rétroextrapolation; modélisation 


\section{Introduction}

In swimming, measuring oxygen uptake $\left(\dot{V}_{\mathrm{o}_{2}}\right)$ is a complex and unwieldy procedure. Recently, portable gas analysers connected to face masks (e.g. (Rodríguez 1995; Rodriguez 2000b) or swimming snorkels (e.g. (Keskinen et al. 2003; Rodríguez et al. 2008; Baldari et al. 2013) have facilitated this task providing the investigators with an acceptable level of practicality and accuracy. Nevertheless, measuring $\dot{V}_{\mathrm{o}_{2}}$ using a swimming snorkel might involve changes in stroke kinematics (Keskinen et al. 2001; Barbosa et al. 2010), swimming technique (e.g. reducing body rolling), and normal breathing pattern, and make impossible diving starts and flip turns (Kjendlie et al. 2003; Kapus et al. 2006).

To solve this problem, Montpetit et al. proposed to use postexercise measurements and the backward extrapolation (BE) method-first described by di Prampero et al. (Di Prampero et al. 1976) and later validated by Léger et al. (Léger et al. 1980) for treadmill running - to swimming, and validated this technique against Douglas bag measures in a multistage free-swimming and treadmill running (Montpetit et al. 1981). In their original study, directly measured exercise $\dot{V} \mathrm{o}_{2 \max }$ was compared with values estimated through the linear $\mathrm{BE}$ of the $\dot{V} \mathrm{o}_{2}$ recovery curve at time zero using semilogarithmic single exponential least squares regression on the first three or four 20 -s bag content values. No significant differences were found between $\dot{V} \mathrm{o}_{2 \text { max }}$ measured and estimated by BE and the standard error of the estimate $\left(S E_{E}\right)$ was $3.7 \%$. From then, $\mathrm{BE}$ is often used for estimating $\dot{V}_{\mathrm{o}_{2}}$ during swimming (Léger et al. 1980; Montpetit et al. 1981; Ricci et al. 1983; Ribeiro et al. 1990; Zamparo et al. 2008; Zamparo et al. 2012), but an error can derive from a delay at the onset of the $\dot{V} \mathrm{o}_{2}$ recovery curve after supramaximal exercise, which has been consistently described as lasting 5-35 s for maximal exercise to up to $1 \mathrm{~min}$ (Di Prampero et al. 1973). In fact, 
Lavoie et al. suggested that this time-variable delay was responsible for the $\sim 20 \%$ overestimation of peak $\dot{V}_{\mathrm{o}_{2}}\left(\dot{V}_{\mathrm{o}_{2 \text { peak }}}\right)$ when using BE after an unimpeded $400-\mathrm{m}$ maximal swim and, to circumvent this problem, they were the first to propose a single 20-s postexercise gas collection during recovery as a good and practical indicator of $\dot{V} \mathrm{o}_{2 \text { peak }}$ in swimming (Lavoie et al. 1983). Two years later, Costill et al. (Costill et al. 1985) further validated this simplified method in tethered breastroke swimming and found a high correlation $\left(r^{2}=0.96\right)$ between exercise and 20 -s recovery $\dot{V} \mathrm{o}_{2 \text { peak }}$, although observing a decline in $\dot{V}_{\mathrm{O}_{2}}(\sim 6 \%)$ during the first $20 \mathrm{~s}$ of recovery. Later, using continuous breath-by-breath $(\mathrm{BxB})$ postexercise measurements, Rodríguez corroborated the existence of a time delay after an all-out 400-m swimming exercise at about 3-10 s at the onset of the $\dot{V}_{\mathrm{o}_{2}}$ recovery phase (Rodríguez 1999). Sousa et al. modelled the $\dot{V}_{\mathrm{o}_{2}}$ kinetics response during and after a square-wave maximal swim at $100 \%$ of $\dot{V}_{\mathrm{o}_{2} \text { peak }}$ using a double-exponential function and reported an average time delay of $11 \mathrm{~s}$ (Sousa et al. 2015). A very recent study reported a time delay of $14.2 \pm 4.7 \mathrm{~s}$ during an all-out 100-m swim, which was longer in female (15.1 s) compared with male swimmers (13.8 s), (Rodríguez et al. 2015, in press).

Recently, a new evaluation procedure based on heart rate (HR) and postexercise $\dot{V} \mathrm{o}_{2}$ measurements for estimating $\dot{V} \mathrm{o}_{2 \text { peak }}$ at the end of a swimming exercise has been implemented (Chaverri et al. 2015, in press). This method showed very highly correlated $\left(r^{2}=0.963\right)$ and practically identical values compared with $\dot{V} \mathrm{o}_{2}$ measured using a swimming snorkel during supramaximal swimming (mean $\Delta=17 \mathrm{ml} \cdot \mathrm{min}^{-1}$ ), hence solving the problem of overestimation. The study also showed an underestimation when $\dot{V} \mathrm{o}_{2 \text { peak }}$ was calculated using a single postexercise 20 -s measurement $(3.3 \pm 1 \%)$. 
Therefore, to elucidate the validity of postexercise $\dot{V} \mathrm{o}_{2}$ measurements in estimating $\dot{V}_{\mathrm{o}_{2 p e a k}}$ in swimming, we compared direct $\dot{V}_{\mathrm{o}_{2}} \mathrm{BxB}$ measurements during supramaximal exercise with various procedures for estimating exercise $\dot{V} \mathrm{o}_{2}$ from measurements during the recovery period, including a recently developed $\mathrm{HR}-\dot{V} \mathrm{o}_{2}$ modelling procedure based on the Fick's principle.

\section{Methods}

\section{Participants}

Thirty-one elite swimmers, all members of national and Olympic teams, including 18 females and 13 males (table 1), gave their written informed consent to participate in the study, which had received approval from the Ethics Committee for Clinical Sport Research of Catalonia and follow the legal requirements and the Declaration of Helsinki (Harriss et al. 2013).

\section{-- Table 1--}

\section{Testing}

After a 30-min standard warm-up, the subjects rested outside the water while the respiratory equipment was set up and calibrated for the measurements. Afterwards the swimmers performed an all-out 200-m front crawl swim using the swimming snorkel (table 1). During the test, an assistant carried the respiratory equipment walking beside the swimmer at the edge of the pool. After exercise the swimmers remained for 3 minutes in an upright position and immersed into the water to the mid-sternum. All tests were conducted at a 50-m indoor pool (altitude $190 \mathrm{~m}$ a.s.1.; water temperature 26-27 $\mathrm{C}$; air temperature $27-28^{\circ} \mathrm{C}$ ).

Data collection and processing 
$\dot{V} \mathrm{o}_{2}$ was measured using a telemetric portable gas analyser ( $\mathrm{K} 4 \mathrm{~b}^{2}$, Cosmed, Italy) connected to the swimmer by a previously validated low hydrodynamic resistance respiratory snorkel and valve system (Keskinen et al. 2003; Rodríguez et al. 2008). Pulmonary gas exchange values during the maximal swim were measured 1 min before, during, and 3 min after exercise. HR was continuously measured using beat-by-beat monitors (CardioSwim, Freelap, Switzerland). Measured $\dot{V} \mathrm{o}_{2}$ and HR data were timealigned to the start of the measurements, 1-s interpolated, and plotted against time.

\section{Measured $\dot{V}_{\mathrm{O}_{2 \text { peak }}}$ during exercise}

Two $\dot{V} \mathrm{o}_{2 \text { peak }}$ values during exercise were identified: 1) $\dot{V} \mathrm{o}_{2 \text { peak }}(-20-0)$ : averaged values measured within the last $20 \mathrm{~s}$ of exercise $\left(t_{-20}-t_{0}\right)$; these values were taken as the criterion value for all comparisons; and 2) $\dot{V}_{\mathrm{o}_{2 p e a k}}$ nonlinear regression $\left(\dot{V}_{\mathrm{o}_{2 \text { peak }}}(\mathrm{NLR})\right)$ : pulmonary $\dot{V}_{\mathrm{o}_{2}}$ values during swimming were measured $\mathrm{BxB}$, timealigned to the start of exercise, and plotted against time. No smoothing procedures were applied to avoid distortion of the underlying signal at the transient phase. $\dot{V} \mathrm{o}_{2}$ data were fitted using a nonlinear least-square regression technique (Matlab R2010b, Mathworks, USA). For the analysis of $\dot{V} \mathrm{o}_{2}$ kinetics, the first two phases of the generally adopted 3phase model were identified, since the exercise duration and intensity constrained the appearance of the slow component (Scheuermann et al. 2003). Phase I (cardiodynamic component) was determined as the time from the onset of exercise to a point of sharper increase in $\dot{V} \mathrm{o}_{2}$, and its duration was computed as a time delay for the primary component $\left(T D_{\mathrm{p}}\right)$. Phase II (principal component) parameters were estimated using a monoexponential model according to the following equation:

$\dot{V}_{\mathrm{o}_{2}}(t)=A_{0}+A_{\mathrm{p}} \cdot\left(1-\mathrm{e}^{-\left(t-\mathrm{TD}_{\mathrm{p}}\right) / \tau_{\mathrm{p}}}\right)$

where $t(\mathrm{~s})$ is the time from the onset of exercise; $A_{0}$ is the baseline amplitude; $A_{\mathrm{p}}$ is the amplitude of the principal component; $T D_{\mathrm{p}}(\mathrm{s})$ is the time delay of the first exponential 
term and equals the duration of phase I (cardiodynamic component); and $\tau_{\mathrm{p}}$ is the time constant of the principal component. The total amplitude $\left(A_{\text {tot }}\right)$ was calculated as $A_{\text {tot }}=$ $A_{0}+A_{\mathrm{p}}$. The reliability of $\dot{V} \mathrm{o}_{2 \text { peak }}$ measurements was characterized by a typical error (TE) of 3.1\% (95\% confidence interval, 95\% CI: $1.1-5.1 \% ; n=9)$.

\section{Estimated $\dot{V}_{\mathrm{O}_{2 \text { peak }}}$ from post-exercise measurements}

Three different techniques were used to estimate $\dot{V} \mathrm{o}_{2 \text { peak }}$ from $\mathrm{HR}$ and/or $\dot{V} \mathrm{o}_{2}$ kinetics during recovery period: 1) lineal $\mathrm{BE}, 2$ ) semilogarithmic $\mathrm{BE}$, and 3) modelling procedures. First, six different procedures were used to estimate $\dot{V} \mathrm{o}_{2 \text { peak }}$ using the linear BE technique: 1) $\dot{V}_{\mathrm{o}_{2 \text { peak }}}(20-0)$ : average values measured within the first $20 \mathrm{~s}$ of recovery $\left.\left(t_{0}-t_{20}\right) ; 2\right) \mathrm{BE}(20)$ : estimated value calculated by BE to time zero $\left(t_{0}\right)$ of the first 20 -s values of the $\dot{V}_{\mathrm{o}_{2}}$ recovery curve; 3) $\mathrm{BE}(30)$ : estimated $\dot{V} \mathrm{o}_{2 \text { peak }}$ by BE to $t_{0}$ of the first 30 -s values of the $\dot{V}_{\mathrm{O}_{2}}$ recovery curve; 4) $\mathrm{BE}(3 \times 20)$ : BE value calculated from the first three 20 -s average values of the $\dot{V}_{\mathrm{O}_{2}}$ recovery curve; 5) $\mathrm{BE}(4 \times 20)$ : $\mathrm{BE}$ value calculated from the first four 20-s average values of the $\dot{V} \mathrm{o}_{2}$ recovery curve; and 6) $\mathrm{BE}(3 \cup 4 \times 20)$ : estimated value calculated by $\mathrm{BE}$ to $t_{0}$ of the best linear regression fit (3x20-s or $4 \times 20$-s) of the $\dot{V}_{\mathrm{o}_{2}}$ recovery curve.

Second, the same estimations were performed using the semilogarithmic procedure (LOG), i.e. plotting the logarithms of the $\dot{V} \mathrm{o}_{2}$ measured values as a function of recovery time and backward extrapolating to $t_{0}$ as in the original paper of Léger et al. (Léger et al. 1980). Using analogous notation, five different calculations were computed to estimate $\left.\left.\left.\left.\dot{V}_{\mathrm{o}_{2 \text { peak }}}: 1\right) \operatorname{LOG}(20) ; 2\right) \operatorname{LOG}(30) ; 3\right) \operatorname{LOG}(3 \times 20) ; 4\right) \operatorname{LOG}(4 \times 20)$; and 5) $\operatorname{LOG}(3 \cup 4 \times 20)$.

Third, $\dot{V} \mathrm{o}_{2 \text { peak }}$ was estimated using a modelling technique: $p \operatorname{Vo}_{2}(0-20): 20$ s averaged values of the predicted $\dot{V} \mathrm{o}_{2}$ based on the $\mathrm{HR}$ and $\dot{V} \mathrm{o}_{2}$ kinetics during the 
recovery period following the procedure previously described by Chaverri et al. (Chaverri et al. 2015, in press). Based on the Fick's principle, the model calculates a predicted $\dot{V}_{\mathrm{O}_{2}}$ at a given time of recovery (t) using changes in $\mathrm{HR}$ as a proxy for changes in cardiac output, and the oxygen pulse as a proxy for the arterio-venous $\mathrm{O}_{2}$ difference according to the equation:

$p \dot{V} \mathrm{o}_{2}(t)=\dot{V} \mathrm{o}_{2}(t) \cdot \mathrm{HR}_{\text {end-exercise }} / \mathrm{HR}(t)$

with, $p \dot{V} \mathrm{o}_{2}(t)$ as the predicted (modelled) postexercise $\dot{V} \mathrm{o}_{2}$ at time $t ; \dot{V} \mathrm{o}_{2}(t)$ as the postexercise 1-s interpolated $\dot{V} \mathrm{O}_{2}$ at time $t ; \mathrm{HR}(t)$ as the postexercise 1-s interpolated HR value at time $t$; and $\mathrm{HR}_{\text {end-exercise }}$ as the highest $\mathrm{HR}$ value of the last $10 \mathrm{~s}$ of exercise (single peaks higher than $5 \mathrm{bpm}$ than the last 10-s HR average excluded).

\section{Statistical analysis}

Descriptive data are expressed as mean and standard deviations $( \pm \mathrm{SD})$, and mean differences (mean $\Delta$ ). The normality of the distributions and homogeneity of variance were checked by the Shapiro-Wilks and Levene tests, respectively. A one-way analysis of variance with repeated measures (RM-ANOVA) and post-hoc Bonferroni test when appropriate were used for multiple comparisons between exercise (criterion value) and each of the postexercise measured and estimated values. Sphericity was checked by Mauchly's sphericity test. The Pearson's coefficient of determination $\left(r^{2}\right)$ was used to assess correlation between variables and the goodness-of-fit of regression models, which was further assessed by using a cross-validation $(\mathrm{CV})$ procedure. Data were split into two half sub-samples $\left(\mathrm{CV}_{1}, \mathrm{CV}_{2}\right)$ and their regression parameters were calculated and then used to estimate a set of predicted values for the other sub-sample. $r^{2}$ for the observed and predicted data for each sub-sample $\left(r^{2}{ }_{\mathrm{CV} 1}, r_{\mathrm{CV} 2}^{2}\right)$ were then computed. The standard error of the estimation $\left(S E_{E}\right)$, expressed as absolute values and \% of the mean, and the limits of the $95 \%$ confidence interval (95\% CI) were calculated. Differences 
between measured and estimated $\dot{V} \mathrm{o}_{2 \text { peak }}$ and the level of agreement (mean $\Delta \pm 1.96 \mathrm{SD}$ ) were analysed graphically using Bland-Altman difference plots (Bland et al. 1986). Under- and overestimation are defined as the difference between estimated and criterion mean values expressed in percentage of the criterion's mean. The level of significance was set at $P<0.05$. Statistical analyses were conducted using SPSS 18.0 for Windows.

\section{Results}

Figure 1 shows $\dot{V}_{\mathrm{o}_{2}}$ measured during the all-out 200-m swim and during recovery, and $\dot{V} \mathrm{o}_{2 \text { peak }}$ estimated during recovery using the various linear BE techniques. The same time intervals were used for the logarithmic BE methods. Irrespectively of the calculation procedure, all $\mathrm{BE}$ techniques overestimated exercise $\dot{V}_{\mathrm{o}_{2 p e a k}}$ as a consequence of the time-variable delay at the immediate recovery $(9.1 \pm 4.8 \mathrm{~s}$; range $=2$ $22 \mathrm{~s} ; 95 \% \mathrm{IC}=7.3-10.9 \mathrm{~s})$.

\section{-- Figure 1 --}

As shown in table $2, \dot{V}_{\mathrm{o}_{2 \text { peak }}}(\mathrm{NLR})$ and $\dot{V}_{\mathrm{o}_{2 \text { peak }}}(-20-0)$ values were very strongly correlated $\left(r^{2}=0.977 ; p<0.001\right)$, although $\dot{V}_{\mathrm{O}_{2 p e a k}}(\mathrm{NLR})$ gave nonsignificant, slightly lower values as compared with the criterion (mean $\Delta=-1.5 \% ; p=1.000$ ). All estimated $\dot{V}_{\mathrm{o}_{2 p e a k}}$ values differed from the criterion, except $\operatorname{BE}(20) \quad(p=0.393)$, $\operatorname{LOG}(20)(p=0.301)$, and $p \dot{V} \mathrm{o}_{2 \text { peak }}(0-20)(p=1.000) \cdot p \dot{V o}_{2 \text { peak }}(0-20)$ predicted values were almost identical (mean $\Delta=1.1 \%$ ) and very strongly correlated with criterion measurements $\left(r^{2}=0.962 ; p<0.001 ; S E_{E}=4.1 \%\right)$. The $r^{2}$ calculated by cross-validation confirms the robustness of the estimations and the validity of the comparisons.

\section{-- Table 2--}


The regression and different plots in figure 2 show a strong correlation $\left(r^{2}=0.962 ; p<0.001\right)$ and a good level of agreement between criterion-exercise $\dot{V} \mathrm{o}_{2 \text { peak }}$ and model-predicted $p V_{o_{2 p e a k}}(0-20)$ values.

\section{-- Figure 2 -}

Figure 3 shows the regression and difference plots for the estimated $\dot{V} \mathrm{o}_{2}$ values using linear BE techniques (see table 1 for statistics). All BE methods except $\dot{V}_{\mathrm{o}_{2 \text { peak }}}(0-20)$ (figure 3.A) overestimated exercise $\dot{V} \mathrm{o}_{2 \text { peak }}$. Larger mean differences and $95 \%$ limits of agreement were common to $\mathrm{BE}(3 \times 20), \mathrm{BE}(4 \times 20)$, and $\mathrm{BE}(3 \cup 4 \times 20)$ (figures 3.D-F), whereas $\mathrm{BE}(20)$ and $\mathrm{BE}(30)$ showed the lowest mean difference and best level of agreement with criterion values (figures 3.A-C). From these parameters, only $\mathrm{BE}(20)$ was not significantly different from the criterion $(p=0.393)$.

\section{-- Figure 3 --}

Figure 4 shows the regression and difference plots for the estimated $\dot{V} \mathrm{o}_{2}$ values using semilogarithmic BE techniques. Again, all techniques overestimated $\dot{V} \mathrm{o}_{2 \text { peak }}$ measured during exercise. Only LOG(20) and LOG(30) (figures 3.A, 3.B) showed a satisfactory level of agreement and high correlations with criterion values $\left(r^{2}=0.949\right.$ and $r^{2}=0.958$, respectively).

\section{-- Figure 4 --}

\section{Discussion}

To assess the validity of postexercise measurements for estimating $\dot{V} \mathrm{o}_{2 \text { peak }}$ in swimming we compared measured $\dot{V}_{\mathrm{o}_{2 p e a k}}$ during a $200-\mathrm{m}$ all-out swim using a respiratory snorkel and $\dot{V} \mathrm{o}_{2 \text { peak }}$ estimated from postexercise values during the same test according to various commonly adopted procedures. The main findings were: 1) post- 
exercise $\dot{V} \mathrm{o}_{2}$ measurements allowed to estimate exercise $\dot{V} \mathrm{o}_{2 \text { peak }}$ in elite competitive swimmers with good accuracy; 2) the overestimation of $\dot{V}_{\mathrm{o}_{2 p e a k}}$ exhibited by the BE methods can be explained by a slower decay of the $\dot{V} \mathrm{o}_{2}$ curve at the onset of the recovery period $(\sim 10 \mathrm{~s}$ on average); 3$)$ the present results confirm our previous observations that the new modelling method based on HR kinetics and postexercise $\dot{V} \mathrm{o}_{2}$ measurements is the most valid and accurate procedure for estimating $\dot{V} \mathrm{o}_{2 \text { peak }}$ after a maximal swim.

Two procedures were used to quantify $\dot{V}_{\mathrm{o}_{2 p e a k}}$ during swimming: $\dot{V}_{\mathrm{o}_{2 \text { peak }}}(-20-0)$ was the 20 -s average at the end of the swim, and $\dot{V} \mathrm{o}_{2 \text { peak }}(\mathrm{NLR})$ was obtained by non-linear double exponential regression. Confirming previous results (Rodríguez et al. 2015), both values did not differ and were nearly perfectly correlated $\left(r^{2}=0.977\right)$, albeit $\dot{V} \mathrm{o}_{2 \text { peak }}(-20-0)$ showed slightly greater values (mean $\left.\Delta=1.5 \%\right)$. We chose $\dot{V} \mathrm{o}_{2 \text { peak }}(-20-0)$ as the reference criterion for all comparisons for a number of reasons (Chaverri et al. 2015, in press): 1) to ensure that only last swimming lap data were used; 2) to minimize inter-breath fluctuations; 3) to prevent overestimation of $\dot{V} \mathrm{o}_{2 \text { peak }}$ values frequently obtained with shorter time intervals (de Jesus et al. 2014); 4) to maintain exercise and recovery temporal equality according to the on/off symmetry in the $\dot{V} \mathrm{O}_{2}$ kinetic response (Sousa et al. 2011a); and 5) previous work showed that 20-s average values produced the same $\dot{V} \mathrm{o}_{2 \text { peak }}$ as the total amplitude obtained by nonlinear fitting of the $\dot{V} \mathrm{o}_{2}$ on-kinetics during 200-m maximal swims (Rodríguez et al. 2015).

Concerning the different approaches used to estimate $\dot{V}_{\mathrm{o}_{2 p e a k}}$ using postexercise $\dot{V} \mathrm{O}_{2}$ measurements, they have in common the advantage of allowing the athlete to swim completely unimpeded (i.e. without mouthpiece, snorkel, and tubing) and to attain maximal exertion without any modification of the swimmer's technique and 
hydrodynamics (i.e. breathing pattern, diving starts and turns and subsequent underwater gliding phase, and body position and drag). This is particularly relevant at high velocity swimming, as in time trials to determine $\dot{V}_{\mathrm{O}_{2 p e a k}}$. It has been shown that maximal velocity attained in 100-m (Barbosa et al. 2010) or 400-m all-out tests (Lavoie et al. 1983) is faster when swimming unimpeded ( $\sim 13-16 \%$ and $\sim 5-6 \%$, respectively), the disparity being explained by the longer distance and the subsequent cumulative effect of altered conditions along the swim. During multistage continuous tests, mean differences of $\sim 10 \%$ in maximal velocity (Keskinen et al. 2001) and in maximal velocity at $\dot{V} \mathrm{o}_{2 \max }$ (Montpetit et al. 1981) were also found.

Notwithstanding, the key issue is whether estimated values from postexercise measurements are in good agreement with those directly measured during exercise. The most straightforward method is collecting expired air during the first $20 \mathrm{~s}$ of the immediate recovery (Lavoie et al. 1983; Costill et al. 1985; Ribeiro et al. 1990). In the present study, $\dot{V}_{\mathrm{O}_{2 \text { peak }}}(0-20)$ underestimated exercise values by $4.5 \%$ (table 2 , figure 3.A), which is in agreement with the original findings of Costill et al., who reported $\sim 6 \%$ lower values using a 20 -s single measure as compared to directly measured $\dot{V}_{\mathrm{o}_{2 \text { peak }}}$ after 5-7 min of tethered swimming at maximal intensity (Costill et al. 1985). A greater underestimation $(\sim 7.6 \%)$ was found by Lavoie et al. after an all-out unimpeded 400-m swim (Lavoie et al. 1983). Here, contrary to these earlier studies, $\dot{V} \mathrm{O}_{2}$ was directly measured $\mathrm{BxB}$, thus allowing to confirm that the bias is caused mainly by a quick decrease of the $\dot{V}_{\mathrm{o}_{2}}$ curve at the onset of the recovery as previously documented in the literature (Di Prampero et al. 1973; Roberts et al. 1978; Rodríguez 1999; Sousa et al. 2011a). In contrast, the other two methods used in the present study and based in short collection periods yet using the BE technique-i.e. linear and semilogarithmic regression from $20-$ and $30-\mathrm{s}$ continuous measurements, 
respectively-overestimated $\dot{V} \mathrm{o}_{2 \text { peak }}$ by 2.4 to $4.2 \%$, though only $\mathrm{BE}(20)$ and $\operatorname{LOG}(20)$ offered values which were not different from the criterion method (table 1; figures 3.B, 4.A). Thus, BE of continuously measured values during $20 \mathrm{~s}$, whether in absolute values or transformed into their logarithms, appears to provide better $\dot{V} \mathrm{o}_{2 \text { peak }}$ estimates than 20-s average of $\mathrm{BxB}$ postexercise measurements or the equivalent 20 -s bag sample classical technique.

\section{$\underline{\text { Backward extrapolation methods }}$}

As to the classical BE methods (i.e. extrapolation to $t_{\mathrm{o}}$ of the recovery of average values obtained during 60 to $80 \mathrm{~s})$, they all provided values which differed $(p<0.001)$ and systematically overestimated (6.2 to $19.7 \%)$ exercise measurements despite showing relatively good correlation with criterion values $\left(r^{2}=0.688\right.$ to 0.950$)$ (table 2 , figures 1 and 2). Lavoie et al. reported a similar overestimation $(\sim 20 \%)$ when using the semilogarithmic BE method (linear regression of three or four 20-s bag samples) after a maximal 400-m swim, and attributed this substantial discrepancy to a time delay in the $\dot{V} \mathrm{o}_{2}$ recovery curve (Lavoie et al. 1983). This phenomenon was first reported by di Prampero et al. who observed that, contrary to steady state aerobic exercise, $\dot{V} \mathrm{O}_{2}$ remains practically at exercise levels for about 12-35 s after cessation of supramaximal leg-cycling exercise of very short duration (11-51 s) (Di Prampero et al. 1973), and was later corroborated for 1-min all-out cycling exercise and quantified in 5-10 s (Tural et al. 2014). An indirect proof is offered by the work of Costill et al. who observed a close correlation between post exercise 20 -s $\dot{V}_{\mathrm{o}_{2}}$ values and $\dot{V}_{\mathrm{o}_{2 p e a k}}\left(r^{2}=0.96\right)$, with a relatively small mean difference $(\sim 6 \%)$, but decreasing correlation during subsequent recovery periods $\left(20-40 \mathrm{~s}, r^{2}=0.94 ; 40-60 \mathrm{~s}, r^{2}=0.52 ; 60-80 \mathrm{~s}, r^{2}=0.59\right)$ (Costill et al. 1985). Later, using BxB equipment, Rodríguez confirmed the existence of a time delay after an all-out 400-m swimming exercise of about 3-10 s at the onset of the $\dot{V}_{\mathrm{O}_{2}}$ 
recovery curve in competitive swimmers (Rodríguez 1997; 1999). Using the same procedure and discarding the individual time delay no significant differences were found between $\dot{V} \mathrm{o}_{2 \max }$ determined with continuous postexercise single 30 -s measurements after a maximal 400-m swimming test compared with $\dot{V} \mathrm{o}_{2 \max }$ measured during maximal incremental cycle ergometer and treadmill tests (Rodriguez 2000a). On a study in which the $\dot{V} \mathrm{o}_{2}$ on- and off-kinetics response was measured after a squarewave swimming exercise at the severe intensity domain (i.e. $100 \%$ of $\dot{V}_{\mathrm{o}_{2 \max }}$ ) sustained during $3.3 \pm 0.4 \mathrm{~min}$ and modelled using a double-exponential regression function, the time delay of the fast component was $10.9 \pm 6.4 \mathrm{~s}$ (Sousa et al. 2015). Finally, a recent study reported a time delay of $14.2 \pm 4.7 \mathrm{~s}$ during an all-out $100-\mathrm{m}$ swim, being longer in female (15.1 s) compared with male swimmers (13.8 s) (Rodríguez et al. 2015, in press). The present results corroborate that the overestimation observed when $\mathrm{BE}$ of 20 to $80 \mathrm{~s}$ values are used to predict $\dot{V} \mathrm{o}_{2 \text { peak }}$ during supramaximal exercise is caused by the time delay during the immediate recovery being that: 1) as evidenced in figure 1 , there is slower decay of the $\dot{V} \mathrm{o}_{2}$ curve at the onset of the recovery period; 2) visual inspection of each $\dot{V}_{\mathrm{o}_{2}}$ curves confirmed a time-variable delay in most swimmers $(9.1 \pm 4.8 \mathrm{~s})$; and 3$)$ there were no differences from the criterion when $\dot{V} \mathrm{o}_{2 \text { peak }}$ was calculated using 20-s sampling averages (i.e. $\mathrm{BE}(20)$ and $\mathrm{LOG}(20)$ ), whereas differences existed in all BE methods when longer sampling times were used. Moreover, a previous validation study using the same mathematical modelling procedure showed that sampling times up to $20 \mathrm{~s}$ offered the smallest estimation bias of $\dot{V}_{\mathrm{o}_{2 \text { peak }}}$ after maximal 200-m tests (Chaverri et al. 2015, in press).

\section{Mathematical modelling procedure}

To avoid the problem of under- and overestimation in BE methods our group developed a mathematical modelling procedure based on $\dot{V} \mathrm{O}_{2}$ off-kinetics and HR on- and off- 
kinetics which gave satisfactory results in predicting end-exercise $\dot{V} \mathrm{o}_{2 \text { peak }}$ following an all-out 200-m swim (Chaverri et al. 2015, in press). In that study, the best end-exercise $\dot{V} \mathrm{o}_{2 \text { peak }}$ estimates were provided by $p \dot{V} \mathrm{o}_{2 \text { peak }}(0-20)$, i.e. values modelled during the first $20 \mathrm{~s}$ of the recovery $\left(r^{2}=0.963\right.$; mean $\left.\Delta=0.5 \% ; S E_{E}=3.8 \%\right)$. Using the same HR- $\dot{V} \mathrm{o}_{2}$ modelling procedure, the present study corroborates its validity and accuracy, as almost identical results were obtained $\left(r^{2}=0.962 ;\right.$ mean $\left.\Delta=1.1 \% ; S E_{E}=4.1 \%\right) \quad$ (table 2, figure 2). Altogether, the present study provides evidence that most methods for determining $\dot{V}_{\mathrm{O}_{2 \text { peak }}}$ from postexercise measurements following a supramaximal swimming effort are most likely to under- or overestimate exercise values as a consequence of the kinetic characteristics of the $\dot{V} \mathrm{o}_{2}$ off-response. As previously discussed, the main reason for the underestimation of the single postexercise 20 -s measurement $(\sim 5-8 \%)$ is the rapid decay of $\dot{V} \mathrm{o}_{2}$ during the immediate recovery (i.e. fast component), characterized by a time constant of $\sim 60-70 \mathrm{~s}$ on average (Sousa et al. 2011a; Sousa et al. 2015). On the other hand, the main cause for the overestimation incurred by all $\mathrm{BE}$ techniques $(\sim 6-20 \%)$ is the time-variable delay of the same fast component which has been quantified in $\sim 11 \pm 6$ $\mathrm{s}$ for all-out swimming exercise (Sousa et al. 2015) and found to be $(9.1 \pm 4.8 \mathrm{~s})$ in this study. Differently, the HR-V $\mathrm{o}_{2}$ modelling procedure is based on the Fick's principle and calculates a predicted $\dot{V}_{\mathrm{O}_{2}}$ at a given time of recovery using the HR as a proxy for changes in cardiac output, and the oxygen pulse as a proxy for the arterio-venous $\mathrm{O}_{2}$ difference (Chaverri et al. 2015, in press). This procedure has shown to provide valid and accurate estimations of exercise $\dot{V} \mathrm{o}_{2 \text { peak }}$ without significant bias (mean $\Delta=0.5$ $1.1 \% ; p=1.0)$.

$\underline{\text { Study limitations }}$

Despite the fact that 200-m maximal swims have been widely adopted in studies with competitive swimmers (Reis et al. 2010; Sousa et al. 2010; Figueiredo et al. 2011; 
Sousa et al. 2011a; Sousa et al. 2011b; Fernandes et al. 2012; Chaverri et al. 2015; Rodríguez et al. 2015), namely because of the very strong activation of both the aerobic and anaerobic energy metabolism (Rodríguez et al. 2011) and its average duration ( 2$2.5 \mathrm{~min}$ on average), sufficient to elicit $\dot{V}_{\mathrm{O}_{2 \max }}$ in most cases (Morgan et al. 1989; Rossiter et al. 2006), it needs to be acknowledged that the present study focused on this particular distance and on the extreme intensity domain. Although we do not anticipate relevant outcome modifications from changes in these two factors, further studies focusing another distances or durations and submaximal intensities are warranted. Likewise, since this study involved elite swimmers, it seems of interest to investigate swimmers of lower competitive level and younger age.

\section{Practical applications}

The use of $\mathrm{BxB}$ respiratory equipment at the poolside has improved the feasibility and validity of gas exchange assessment in swimming. Using specifically designed snorkels, despite the advantage of allowing continuous measurements during exercise and recovery, still faces some limitations such as precluding diving starts and flip turns, changing stroke kinematics, modifying the breathing pattern and causing a sometimes unbearable discomfort. Using postexercise $\dot{V} \mathrm{O}_{2}$ measurements allows the swimmers to exercise completely unimpeded and to exploit their maximal potential with any undue limitation caused by the equipment whatsoever. Nevertheless, as the present results show, the BE technique results in substantial overestimation of $\dot{V} \mathrm{o}_{2 \text { peak }}(\sim 6-20 \%)$. Using regression techniques on $\mathrm{BxB}$ data is likely to reduce measurement error $(2-3 \%$; $p=0.3-0.4$, hence providing a greater level of accuracy in $\dot{V} \mathrm{o}_{2 \text { peak }}$ measurements. Considering that the swimmers typically vary their individual performance in the range of about $\sim 3 \%$ across the competitive season (Pyne et al. 2001; Anderson et al. 2006), the large measurement error reported by BE techniques (linear and semilogarithmic) 
compromise their ability to monitor progress in elite swimmers. Instead, using the proposed model minimizes the error in predicting $\dot{V}_{\mathrm{o}_{2 \text { peak }}}(1.1 \%)$ and provides a valid and accurate method to measure progress in high-level athletes. Moreover, these HR measurements, can be taken without any interference to the normal swimming pattern and can provide scientific and coaches additional information-e.g. training load (García-Ramos et al. 2014). Important to note that some technical conditions are required to ensure the validity of the results (Chaverri et al. 2015, in press): 1) obtaining quality beat-to-beat $\mathrm{HR}$ recordings, 2) obtaining the first $\mathrm{BxB} \dot{V}_{\mathrm{O}_{2}}$ values as fast as possible while avoiding missing breaths and hyperventilation, and 3) monitoring HR and $\dot{V} \mathrm{o}_{2}$ during the recovery period for at least $20 \mathrm{~s}$.

\section{Conclusions}

Measurement accuracy is key to postexercise gas exchange assessment in pool conditions for estimating exercise $\dot{V} \mathrm{o}_{2 \text { peak }}$. From the present study, in which measured $\dot{V}_{\mathrm{o}_{2 \text { peak }}}$ during 200-m maximal swimming exercise was compared with $\dot{V}_{\mathrm{o}_{2 \text { peak }}}$ estimations from postexercise measurements according to various commonly adopted procedures in elite swimmers, we may derive the following conclusions: 1) some (but not all) postexercise $\dot{V} \mathrm{o}_{2}$ estimation techniques allowed to predict exercise $\dot{V}_{\mathrm{o}_{2 p e a k}}$ with good accuracy; 2) the large overestimation exhibited by the classical BE methods ( $\sim 6-20 \%)$ can be explained by a time-variable delay of the fast component of the $\dot{V}_{\mathrm{o}_{2}}$ off-kinetic response $(\sim 10 \mathrm{~s}$ on average); 3) BE methods using linear and semilogarithmic regression of shorter measurement periods $(0-20 \mathrm{~s})$ provided more accurate results, but still overestimate $\dot{V} \mathrm{o}_{2 \text { peak }}$ by $\sim 2-3 \%$, respectively; 4) the widely adopted 20 -s average method underestimates $\dot{V} \mathrm{o}_{2 \text { peak }}$ by $\sim 5 \%$ because of the rapid 
decrease of $\dot{V} \mathrm{o}_{2}$ during the immediate recovery (fast component); and 5) the HR- $\dot{V} \mathrm{o}_{2}$ modelling technique, based on continuous beat-to-beat HR and postexercise breath-bybreath $\dot{V} \mathrm{o}_{2}$ measurements during $20 \mathrm{~s}$, is confirmed as a valid and accurate procedure for estimating $\dot{V} \mathrm{o}_{2 \text { peak }}$ in competitive swimmers without significant bias (0.5-1.1\%). Therefore, the HR- modelling technique appear as the method of choice for assessing cardiorespiratory and metabolic fitness in competitive swimmers when postexercise measurements are chosen to avoid the burden of respiratory equipment during swimming exercise.

\section{Conflict of interest}

The authors declare that there are no conflicts of interest.

\section{Acknowledgements}

We gratefully acknowledge the coaches, staff and all the swimmers who participated in the study and gave their valuable time and effort. Special thanks are given to Dr. Belén Feriche (Universidad de Granada), Dr. Carmen Calderón (High Performance Centre of Sierra Nevada), Dr. Esa Hynynen (KIHU-Research Institute for Olympic Sports of Finland), Dr. Marek Anestik (Scottish Institute of Sport), and Prof. Boro Štrumbelj (Univerzi v Ljubljani, Slovenia) for their help in data collection.

This work was supported by grants awarded by the Ministry of Science and Innovation of Spain (Ministerio de Ciencia e Innovación, DEP2009-09181) and the Higher Sports Council of Spain (Consejo Superior de Deportes 35/UPB/10, 005/UPB10/11, 112/UPB10/12). Support was granted by the Institut Nacional d'Educació Física de Catalunya (INEFC), Generalitat de Catalunya. Diego Chaverri was supported by research grants awarded by the Agency for Management of University and 
Research Grants of the Catalan Government (AGAUR, Generalitat de Catalunya, PRE/2730/2012) and the Higher Sports Council of Spain (Consejo Superior de Deportes 005/UPB10/11, 112/UPB10/12).

\section{References}

Anderson, M.E., Hopkins, W.G., Roberts, A.D., and Pyne, D.B. 2006. Monitoring seasonal and long-term changes in test performance in elite swimmers. Eur J Sport Sci 6: 145-154.

Baldari, C., Fernandes, R.J., Meucci, M., Ribeiro, J., Vilas-Boas, J.P., and Guidetti, L. 2013. Is the new AquaTrainer(R) snorkel valid for VO2 assessment in swimming? Int J Sports Med 34: 336-44.

Barbosa, T., Silva, A.J., Reis, A.M., Costa, M., Garrido, N., Policarpo, F., and Reis, V.M. 2010. Kinematical changes in swimming front crawl and breaststroke with the AquaTrainer snorkel. Eur J Appl Physiol 109: 1155-62.

Bland, J.M. and Altman, D.G. 1986. Statistical methods for assessing agreement between two methods of clinical measurement. The Lancet 327: 307-310.

Chaverri, D., Schuller, T., Iglesias, X., Hoffmann, U., and Rodríguez, F.A. 2015. A new model for estimating peak VO2 based on post-exercise measurements in swimming. Int J Sports Physiol Perform: [Epub ahead of print].

Costill, D.L., Kovaleski, J., Porter, D., Kirwan, J., Fielding, R., and King, D. 1985. Energy expenditure during front crawl swimming: predicting success in middledistance events. Int J Sports Med 6: 266-70.

de Jesus, K., Guidetti, L., de Jesus, K., Vilas-Boas, J.P., Baldari, C., and Fernandes, R.J. 2014. Which are the best VO2 sampling intervals to characterize low to severe swimming intensities? Int J Sports Med 35: 1030-1036. 
Di Prampero, P.E., Cortili, G., Mognoni, P., and Saibene, F. 1976. Energy cost of speed skating and efficiency of work against air resistance. J Appl Physiol 40: 584-91.

Di Prampero, P.E., Peeters, L., and Margaria, R. 1973. Alactic O 2 debt and lactic acid production after exhausting exercise in man. J Appl Physiol 34: 628-32.

Fernandes, R.J., de Jesus, K., Baldari, C., de Jesus, K., Sousa, A.C., Vilas-Boas, J.P., and Guidetti, L. 2012. Different VO2max time-averaging intervals in swimming. Int J Sports Med 33: 1010-5.

Figueiredo, P., Zamparo, P., Sousa, A., Vilas-Boas, J.P., and Fernandes, R.J. 2011. An energy balance of the $200 \mathrm{~m}$ front crawl race. Eur J Appl Physiol 111: 767-77.

García-Ramos, A., Feriche, B., Calderón, C., Iglesias, X., Barrero, A., Chaverri, D., Schuller, T., and Rodríguez, F.A. 2014. Training load quantification in elite swimmers using a modified version of the training impulse method. Eur J Sport Sci 15(2): 85-93.

Harriss, D.J. and Atkinson, G. 2013. Ethical standards in sport and exercise science research: 2014 update. Int J Sports Med 34: 1025-1028.

Kapus, J., Strumbelj, B., Usaj, A., and Kapus, V. 2006. The breathing frequency changes during swimming by using respiratory valves and tubes. Port J Sport Sci (Biomechanics and Medicine in Swimming X) 6: 229-231.

Keskinen, K., Keskinen, O., and Rodríguez, F.A. 2001. Effect of a respiratory snorkel and valve system on front crawl kinematics during standardised pool testing.In: J. Mester, G. King, H. Strüder, E. Tsolakidis, and A. Osterburg (Eds.), 6th Annual Congress of the European College of Sport Science, p. 538. Cologne: Sport und Buch Strauss. 
Keskinen, K.L., Rodríguez, F.A., and Keskinen, O.P. 2003. Respiratory snorkel and valve system for breath-by-breath gas analysis in swimming. Scand J Med Sci Sports 13: 322-329.

Kjendlie, P.L., Stallman, R., and Stray-Gundersen, J. 2003. Influences of a breathing valve on swimming technique.In: J.C. Chatard (Eds.), Biomechanics and Medicine In Swimming IX, pp. 69-73. Saint-Étienne: Publications de l'Université de SaintÉtienne.

Lavoie, J.-M., Léger, L.A., Montpetit, R.R., and Chabot, S. 1983. Backward extrapolation of $\mathrm{VO} 2$ from the $\mathrm{O} 2$ recovery curve after a voluntary maximal 400m swim.In: A.P. Hollander, P.A. Huijing, andG. De Groot (Eds.), Biomechanics and Medicine in Swimming, pp. 222-227: Human Kinetics, Champaign, Illinois.

Léger, L.A., Seliger, V., and Brassard, L. 1980. Backward extrapolation of VO2max values from the O2 recovery curve. Med Sci Sports Exerc 12: 24-7.

Montpetit, R.R., Léger, L.A., Lavoie, J.M., and Cazorla, G. 1981. VO2 peak during free swimming using the backward extrapolation of the O2 recovery curve. Eur J Appl Physiol Occup Physiol 47: 385-91.

Morgan, D.W., Baldini, F.D., Martin, P.E., and Kohrt, W.M. 1989. Ten kilometer performance and predicted velocity at $\mathrm{VO} 2 \mathrm{max}$ among well-trained male runners. Med Sci Sports Exerc 21: 78-83.

Pyne, D.B., Lee, H., and Swanwick, K.M. 2001. Monitoring the lactate threshold in world-ranked swimmers. Med Sci Sports Exerc 33: 291-7.

Reis, V.M., Marinho, D.A., Policarpo, F.B., Carneiro, A.L., Baldari, C., and Silva, A.J. 2010. Examining the accumulated oxygen deficit method in front crawl swimming. Int J Sports Med 31: 421-427. 
Ribeiro, J.P., Cadavid, E., Baena, J., Monsalvete, E., Barna, A., and De Rose, E.H. 1990. Metabolic predictors of middle-distance swimming performance. Br J Sports Med 24: 196-200.

Ricci, J. and Leger, L.A. 1983. VO2max of cyclists from treadmill, bicycle ergometer and velodrome tests. Eur J Appl Physiol Occup Physiol 50: 283-9.

Roberts, A.D. and Morton, A.R. 1978. Total and alactic oxygen debts after supramaximal work. Eur J Appl Physiol Occup Physiol 38: 281-9.

Rodríguez, F., Lätt, E., Jürimäe, J., Maestu, J., Purge, P., Rämson, R., Haljaste, K., Keskinen, K.L., and Jürimäe, T. 2015. VO2 kinetics in all-out arm stroke, leg kick and whole stroke front crawl 100-m swimming. Int J Sports Med: [Epub ahead of print].

Rodríguez, F.A. 2000. Maximal oxygen uptake and cardiorespiratory response to maximal 400-m free swimming, running and cycling tests in competitive swimmers. J Sports Med Phys Fitness 40: 87-95.

Rodríguez, F.A. 1995. Peak oxygen uptake after a 400-m test as a measure of maximal aerobic power in competitive swimmers. Glyfada, Athens, Greece, p. 44: FINA.

Rodríguez, F.A. 1997. Metabolic evaluation of swimmers and water polo players. Kinesiology. Journal of Biology of Exercise 2: 19-29.

Rodríguez, F.A. 1999. Cardiorespiratory and metabolic field testing in swimming and water polo: from physiological concepts to practical methods. In: K.L. Keskinen, P.V. Komi, and A.P. Hollander (Eds.), Biomechanics and Medicine in Swimming VIII, pp. 219-226. University of Jyväskylä, Finland: Gummerus Printing.

Rodríguez, F.A., Iglesias, X., Feriche, B., Calderon-Soto, C., Chaverri, D., Wachsmuth, N.B., Schmidt, W., and Levine, B.D. 2015. Altitude training in elite swimmers for sea level performance (Altitude Project). Med Sci Sports Exerc 47: 1965-78. 
Rodríguez, F.A., Keskinen, K.L., Kusch, M., and Hoffmann, U. 2008. Validity of a swimming snorkel for metabolic testing. Int J Sports Med 29: 120-8.

Rodríguez, F.A. and Mader, A. 2011. Energy systems in swimming. In: L. Seifert, D. Chollet, and I. Mujika (Eds.), World Book of Swimming: From Science to Performance, pp. 225-240. Hauppauge, New York: Nova Science Publishers.

Rossiter, H.B., Kowalchuk, J.M., and Whipp, B.J. 2006. A test to establish maximum O2 uptake despite no plateau in the $\mathrm{O} 2$ uptake response to ramp incremental exercise. J Appl Physiol 100: 764-70.

Scheuermann, B.W. and Barstow, T.J. 2003. O2 uptake kinetics during exercise at peak O2 uptake. J Appl Physiol 95: 2014-22.

Sousa, A., Figueiredo, P., Keskinen, K.L., Rodríguez, F.A., Machado, L., Vilas-Boas, J.P., and Fernandes, R.J. 2011. VO2 off transient kinetics in extreme intensity swimming. J Sports Sci Med 10: 546-52.

Sousa, A., Figueiredo, P., Oliveira, N., Oliveira, J., Keskinen, K., Vilas-Boas, J., and Fernandes, R. 2010. Comparison between swimming VO2peak and VO2max at different time intervals. Open Sports Sci J 3: 22-24.

Sousa, A., Rodriguez, F.A., Machado, L., Vilas-Boas, J.P., and Fernandes, R.J. 2015. Exercise modality effect on VO off-transient kinetics at VO intensity. Exp Physiol. 100(6): 719-29.

Sousa, A.C., Figueiredo, P., Oliveira, N.L., Oliveira, J., Silva, A.J., Keskinen, K.L., Rodríguez, F.A., Machado, L.J., Vilas-Boas, J.P., and Fernandes, R.J. 2011 b. VO2 kinetics in 200-m race-pace front crawl swimming. Int J Sports Med 32: 765-70.

Zamparo, P., Lazzer, S., Antoniazzi, C., Cedolin, S., Avon, R., and Lesa, C. 2008. The interplay between propelling efficiency, hydrodynamic position and energy cost of front crawl in 8 to 19-year-old swimmers. Eur J Appl Physiol 104: 689-99. 
Zamparo, P. and Swaine, I.L. 2012. Mechanical and propelling efficiency in swimming derived from exercise using a laboratory-based whole-body swimming ergometer. $\mathrm{J}$ Appl Physiol (1985) 113: 584-94. 
Table 1. Subjects characteristics and 200-m all-out swimming test performance

\begin{tabular}{lccc}
\hline & Females $(\mathrm{n}=18)$ & Males $(\mathrm{n}=13)$ & All $(\mathrm{n}=31)$ \\
\hline Age (years) & $20.3 \pm 3.8$ & $22.2 \pm 2.9$ & $21.1 \pm 3.5$ \\
Height $(\mathrm{cm})$ & $172.9 \pm 5.4$ & $187.9 \pm 6.0$ & $179.2 \pm 9.4$ \\
Body mass (kg) & $63.3 \pm 5.4$ & $82.1 \pm 7.2$ & $71.2 \pm 11.2$ \\
FPS* & $856 \pm 75$ & $840 \pm 44$ & $849 \pm 63$ \\
Time 200 m (s) & $144.3 \pm 7.1$ & $135.8 \pm 8.1$ & $140.7 \pm 8.5$ \\
Mean velocity 200 $\mathrm{m}\left(\mathrm{m} \cdot \mathrm{s}^{-1}\right)$ & $1.389 \pm 0.066$ & $1.478 \pm 0.085$ & $1.426 \pm 0.086$ \\
\hline Values are mean & & &
\end{tabular}

Values are mean \pm SD; * FPS: FINA Point Scores 
Table 2. Peak $\dot{V}_{\mathrm{O}_{2}}$ measured during exercise and peak $\dot{V}_{\mathrm{O}_{2}}$ values measured and estimated by different procedures during recovery.

\begin{tabular}{|c|c|c|c|c|c|c|c|c|c|c|c|c|}
\hline \multirow[t]{2}{*}{ Technique } & \multirow[t]{2}{*}{ Procedure } & \multirow{2}{*}{$\begin{array}{l}\text { Peak } \dot{V}_{\mathrm{O}_{2}} \\
\left(\mathrm{ml} \cdot \mathrm{min}^{-1}\right)\end{array}$} & \multicolumn{2}{|c|}{$95 \% \mathrm{CI}$} & \multicolumn{2}{|c|}{ Mean diff. } & \multirow[t]{2}{*}{$r^{2}$} & \multicolumn{2}{|c|}{$\mathrm{CV} r^{2}$} & \multicolumn{2}{|l|}{$S E_{E}$} & \multirow{2}{*}{$\begin{array}{c}\text { Significance* } \\
\text { (p-value) }\end{array}$} \\
\hline & & & $(\mathrm{ml}$ & $\left.\operatorname{in}^{-1}\right)$ & $\left(\mathrm{ml} \cdot \mathrm{min}^{-1}\right)$ & $(\%)$ & & $r_{C V 1}^{2}$ & $r_{C V 2}^{2}$ & $\left(\mathrm{ml} \cdot \min ^{-1}\right)$ & $(\%)$ & \\
\hline \multirow{2}{*}{$\begin{array}{l}\text { Exercise } \\
\text { (criterion) }\end{array}$} & $\dot{V}_{\mathrm{o}_{2 \text { peak }}}(-20-0)$ & $3531 \pm 738$ & 3260 & 3802 & - & - & - & - & - & - & - & - \\
\hline & $\dot{V} \mathrm{o}_{2 \text { peak }}(\mathrm{NLR})$ & $3479 \pm 727$ & 3213 & 3746 & -52 & -1.5 & 0.977 & 0.966 & 0.991 & 113.5 & 3.2 & 1.000 \\
\hline \multirow[t]{6}{*}{ Lineal BE } & $\dot{V}_{\mathrm{o}_{2 \text { peak }}}(0-20)$ & $3378 \pm 698$ & 3122 & 3635 & -153 & -4.5 & 0.969 & 0.969 & 0.974 & 132 & 3.7 & $<0.001 *$ \\
\hline & $\mathrm{BE}(20)$ & $3617 \pm 708$ & 3357 & 3876 & 86 & 2.4 & 0.956 & 0.959 & 0.962 & 216 & 5.6 & 0.393 \\
\hline & $\mathrm{BE}(30)$ & $3658 \pm 719$ & 3394 & 3921 & 127 & 3.5 & 0.967 & 0.968 & 0.972 & 136 & 3.6 & $0.001 *$ \\
\hline & $\mathrm{BE}(3 \times 20)$ & $3828 \pm 762$ & 3549 & 4107 & 297 & 7.8 & 0.950 & 0.954 & 0.953 & 169 & 4.8 & $<0.001 *$ \\
\hline & $\mathrm{BE}(4 \times 20)$ & $3763 \pm 780$ & 3477 & 4049 & 232 & 6.2 & 0.924 & 0.947 & 0.928 & 207 & 5.9 & $<0.001 *$ \\
\hline & $\mathrm{BE}(3 \cup 4 \mathrm{X} 20)$ & $3823 \pm 746$ & 3549 & 4096 & 292 & 7.6 & 0.946 & 0.957 & 0.944 & 175 & 5.0 & $<0.001^{*}$ \\
\hline Semilogarithmic & $\operatorname{LOG}(20)$ & $3627 \pm 711$ & 3366 & 3888 & 96 & 2.6 & 0.949 & 0.950 & 0.959 & 169 & 4.8 & 0.301 \\
\hline \multirow[t]{4}{*}{$\mathrm{BE}$} & $\operatorname{LOG}(30)$ & $3686 \pm 722$ & 3421 & 3951 & 155 & 4.2 & 0.958 & 0.956 & 0.970 & 154 & 4.3 & $<0.001^{*}$ \\
\hline & $\operatorname{LOG}(3 \times 20)$ & $4175 \pm 768$ & 3894 & 4457 & 644 & 15.4 & 0.863 & 0.874 & 0.864 & 278 & 7.9 & $<0.001 *$ \\
\hline & $\operatorname{LOG}(4 \times 20)$ & $4400 \pm 884$ & 4076 & 4724 & 869 & 19.7 & 0.688 & 0.852 & 0.616 & 420 & 11.9 & $<0.001^{*}$ \\
\hline & $\operatorname{LOG}(3 \cup 4 \times 20)$ & $4302 \pm 819$ & 4002 & 4602 & 771 & 17.9 & 0.772 & 0.885 & 0.694 & 358 & 10.1 & $<0.001^{*}$ \\
\hline Modelling & $p \dot{V} \mathrm{o}_{2 \text { peak }}(0-20)$ & $3571 \pm 735$ & 3301 & 3841 & 40 & 1.1 & 0.962 & 0.955 & 0.977 & 146 & 4.1 & 1.000 \\
\hline
\end{tabular}

Values are mean $\pm S D .95 \%$ CI, 95\% confidence interval; \%, percent of criterion value; Mean diff., mean difference with criterion value; $r^{2}$,

Pearson's coefficient of determination; CV, double cross-validation (CV1 and CV2 are half-split subsamples used for CV); $S E_{E}$, standard error of estimate; Significance, ANOVA RM and post-hoc Bonferroni when appropriate was used to compare each procedure with the criterion value;

*Significantly different from criterion value $(p<0.05$. 


\section{Figure Captions}

Figure 1. Schematic diagram of $\dot{V}_{\mathrm{o}_{2}}$ (grey line, average 1-s values for the entire group of swimmers) measured during exercise (shadowed area) and recovery at a 200-m allout swim. Discontinuous grey lines illustrate time limits (s) in which $\dot{V} \mathrm{o}_{2}$ values were averaged (black dots, mean $\pm \mathrm{SD}$ ) or where regression was applied. The regression lines (both linear and semilogarithmic) projected on the $t_{0}$ of recovery, were used to estimate $\dot{V} \mathrm{o}_{2 \text { peak }}$ using the different $\mathrm{BE}$ procedures. Only linear BE regressions are shown here for clarity. See text for definitions and details.

Figure 2. Relationship between exercise $\dot{V} \mathrm{o}_{2 \text { peak }}$ values -i.e. $\dot{V} \mathrm{o}_{2 \text { peak }}(-20-0)$, xaxis—and $\dot{V}_{\mathrm{o}_{2 p e a k}}$ estimated using the $\mathrm{HR}-\dot{V}_{\mathrm{o}_{2}}$ modelling procedure-i.e $p \dot{V} \mathrm{o}_{2 \text { peak }}(0-20)$, y-axis) Males (grey dots) and females (black dots) are shown separately. In the left panel, regression line (solid back) and equality line (dashed grey) are shown. Linear regression equation and coefficient of determination are shown in the left panel. In the right panel, the $\mathrm{x}$-axis represents mean $\dot{V} \mathrm{o}_{2}\left(\mathrm{ml} \cdot \mathrm{min}^{-1}\right)$ and the $\mathrm{y}$-axis shows the differences with exercise $\dot{V} \mathrm{o}_{2}$. Lines are equality (solid), mean difference (long-dashed), and $\pm 95 \%$ limits of agreement (short-dashed). All data are expressed in $\mathrm{mlO}_{2} \cdot \mathrm{min}^{-1}$.

Figure 3. Relationship between exercise $\dot{V} \mathrm{o}_{2 \text { peak }}$ values - i.e. $\dot{V} \mathrm{o}_{2 \text { peak }}(-20-0)$, xaxis) - and $\dot{V}_{\mathrm{o}_{2 \text { peak }}}$ estimated using different linear BE methods: A) $\dot{V} \mathrm{o}_{2 \text { peak }}(0-20)$, B) $\mathrm{BE}(20)$, C) $\mathrm{BE}(30), \mathrm{D}) \mathrm{BE}(2 \times 20), \mathrm{E}) \mathrm{BE}(4 \times 20)$, and F) $\mathrm{BE}(3 \cup 4 \times 20)$. Regression and difference Bland-Altman plots are presented as in figure 2. See text for definitions and details. 
Figure 4. Relationship between exercise $\dot{V}_{\mathrm{o}_{2 \text { peak }}}$ values -i.e. $\dot{V}_{\mathrm{o}_{2 \text { peak }}}(-20-0)$, $\mathrm{x}-$ axis)_and $\dot{V} \mathrm{o}_{2 \text { peak }}$ estimated using different linear semilogarithmic BE methods: A) LOG(20), B) $\operatorname{LOG}(30)$, C) $\operatorname{LOG}(3 \times 20)$, D) $\operatorname{LOG}(4 \times 20)$, and $E) \operatorname{LOG}(3 \cup 4 \times 20)$. Regression and difference Bland-Altman plots are presented as in figures 2 and 3. See text for definition and details. 


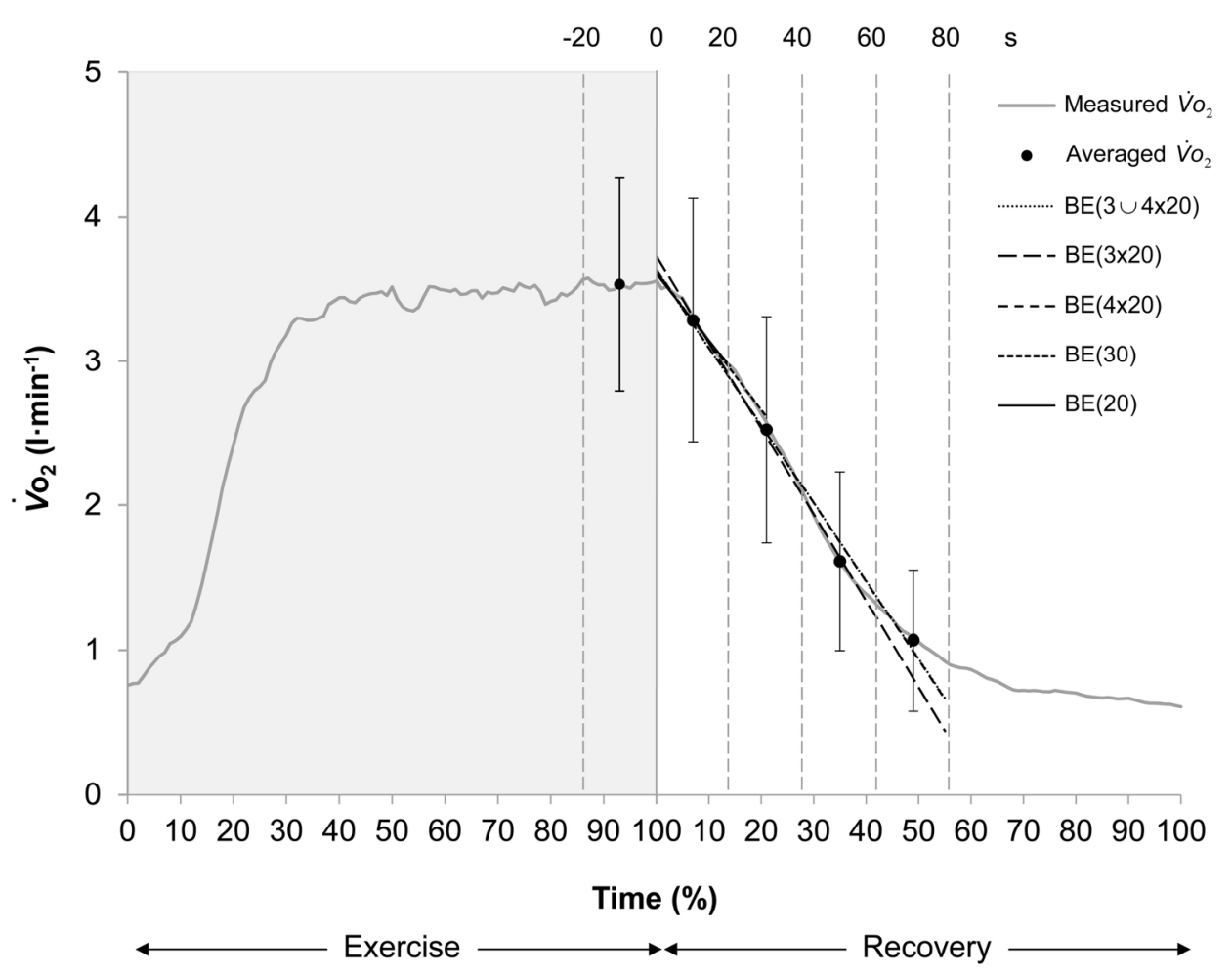

Figure 1. Schematic diagram of $\mathrm{V}^{\prime} \mathrm{O}_{2}$ (grey line, average 1-s values for the entire group of swimmers) measured during exercise (shadowed area) and recovery at a 200-m all-out swim. Discontinuous grey lines illustrate time limits (s) in which $\mathrm{V}^{\prime} \mathrm{O}_{2}$ values were averaged (black dots, mean $\pm \mathrm{SD}$ ) or where regression was applied. The regression lines (both linear and semilogarithmic) projected on the t0 of recovery, were used to estimate $\mathrm{V}^{\prime} \mathrm{O}_{2 \text { peak }}$ using the different BE procedures. Only linear BE regressions are shown here for clarity. See text for definitions and details. $166 \times 134 \mathrm{~mm}(300 \times 300 \mathrm{DPI})$ 

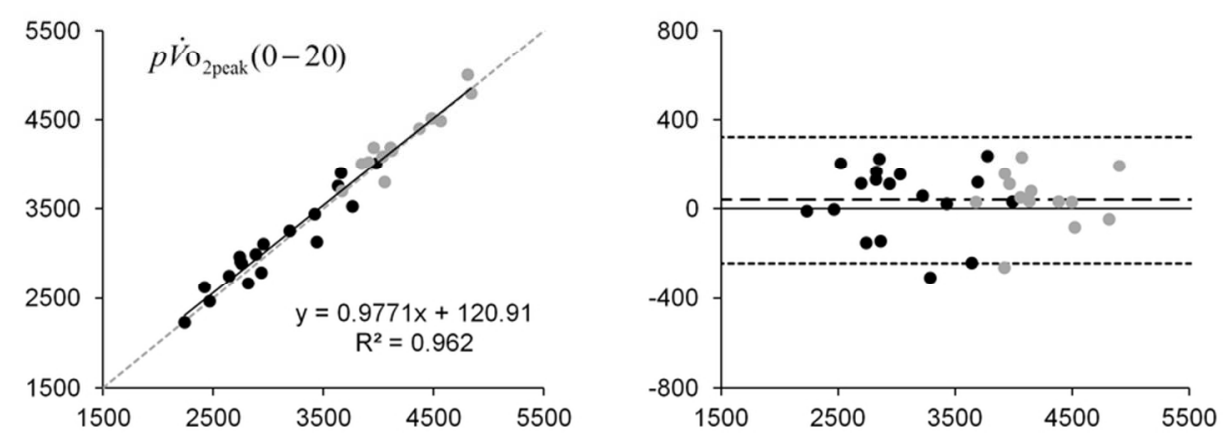

Figure 2. Relationship between exercise $\mathrm{V}^{\prime} \mathrm{O}_{2 \text { peak }}$ values -i.e. $\mathrm{V}^{\prime} \mathrm{O}_{2 \text { peak, }}$ x-axis-and $\mathrm{V}^{\prime} \mathrm{O}_{2 \text { peak }}$ estimated using the $\mathrm{HR}-\mathrm{V}^{\prime} \mathrm{O}_{2}$ modelling procedure-i.e. $\mathrm{pV}^{\prime} \mathrm{O}_{2 \text { peak, }} \mathrm{y}$-axis). Males (grey dots) and females (black dots) are shown separately. In the left panel, regression line (solid back) and equality line (dashed grey) are shown. Linear regression equation and coefficient of determination are shown in the left panel. In the right panel, the $x-$ axis represents mean $\mathrm{V}^{\prime} \mathrm{O}_{2}\left(\mathrm{ml} \cdot \mathrm{min}^{-1}\right)$ and the $\mathrm{y}$-axis shows the differences with exercise $\mathrm{V}^{\prime} \mathrm{O}_{2}$. Lines are equality (solid), mean difference (long-dashed), and $\pm 95 \%$ limits of agreement (short-dashed). All data are expressed in $\mathrm{mlO}_{2} 2 \cdot \mathrm{min}^{-1}$.

$79 \times 35 \mathrm{~mm}(300 \times 300 \mathrm{DPI})$ 
A

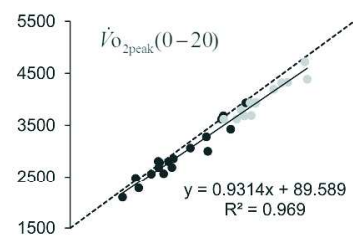

B

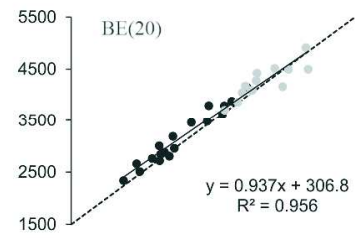

C

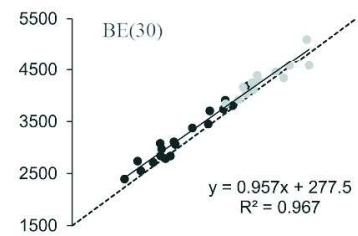

D

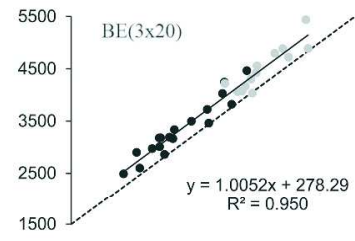

E

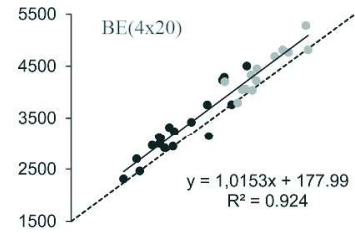

F

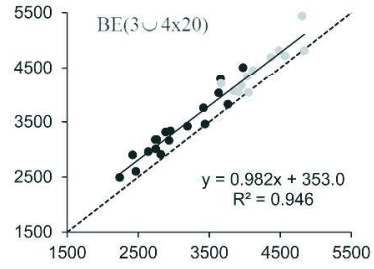

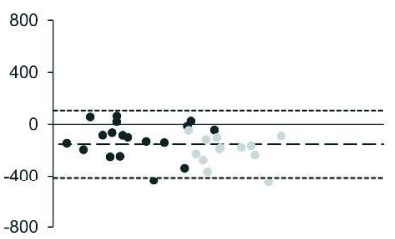
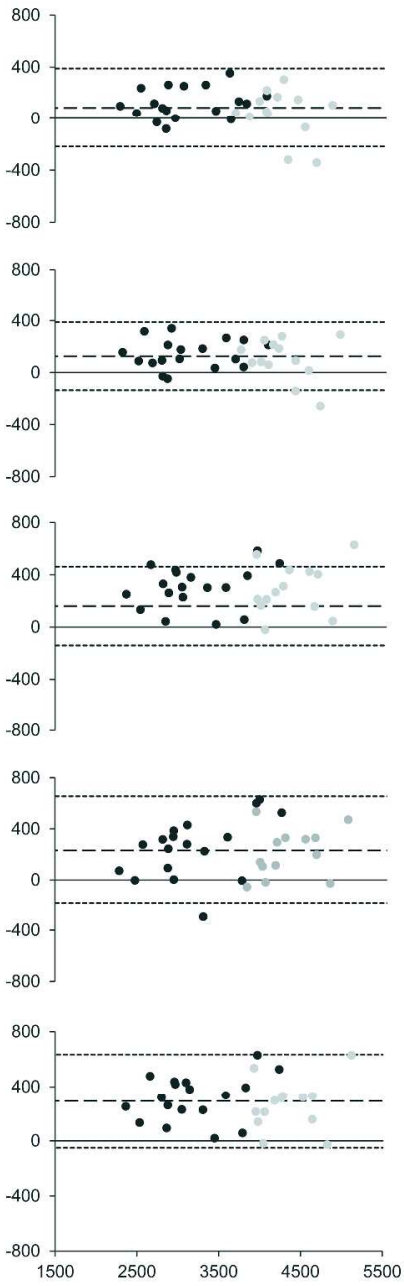

Figure 3. Relationship between exercise $\mathrm{V}^{\prime} \mathrm{O}_{2 \text { peak }}$ values -i.e. $\mathrm{V}^{\prime} \mathrm{O}_{2 \text { peak }}(-20-0), \mathrm{x}$-axis)-and estimated using different linear $\mathrm{BE}$ methods: A) $\left.\left.\left.\left.\mathrm{V}^{\prime} \mathrm{O}_{2 \text { peak }}(0-20), \mathrm{B}\right) \mathrm{BE}(20), \mathrm{C}\right) \mathrm{BE}(30), \mathrm{D}\right) \mathrm{BE}(2 \times 20), \mathrm{E}\right) \mathrm{BE}(4 \times 20)$, and F) $\mathrm{BE}(3 \cup 4 \times 20)$. Regression and difference Bland-Altman plots are presented as in figure 2 . See text for definitions and details. $318 \times 540 \mathrm{~mm}$ (300 x 300 DPI) 

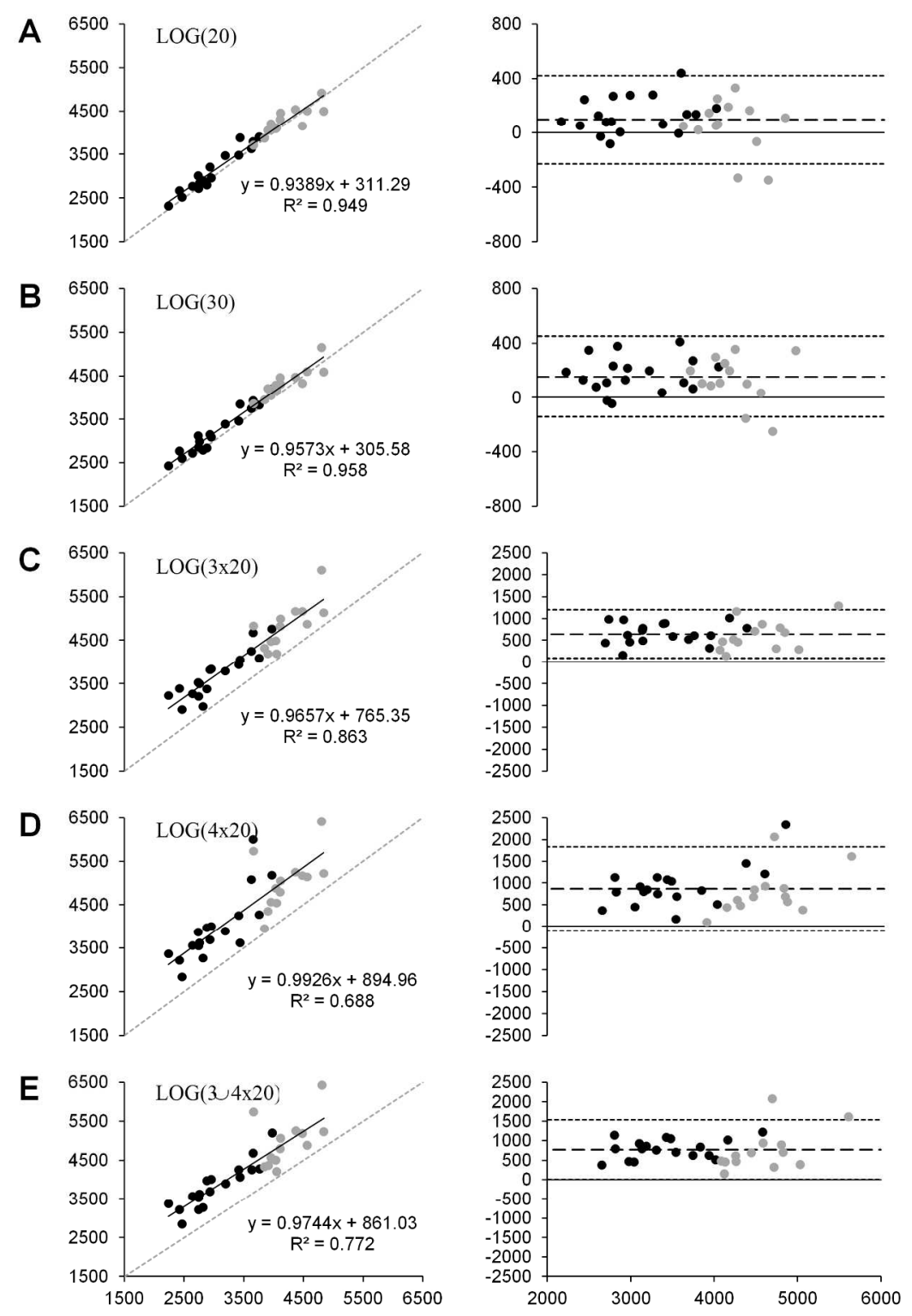

Figure 4. Relationship between exercise $\mathrm{V}^{\prime} \mathrm{O}_{2 \text { peak }}$ values -i.e. $\mathrm{V}^{\prime} \mathrm{O}_{2 \text { peak }}(-20-0), \mathrm{x}$-axis)-and $\mathrm{V}^{\prime} \mathrm{O}_{2}$ estimated using different linear semilogarithmic BE methods: A) LOG(20), B) LOG(30), C) LOG(3x20), D) LOG(4x20), and E) LOG(3U4×20). Regression and difference Bland-Altman plots are presented as in figures 2 and 3 . See text for definition and details. $189 \times 260 \mathrm{~mm}(300 \times 300 \mathrm{DPI})$ 